\title{
Direct Observation of the Solidification Phenomenon of a Tin-Lead Alloy
}

\author{
By Jiandong Xing*, Tetsuichi Motegi** and Atsumi Ohno**
}

\begin{abstract}
The solidification phenomenon was directly observed through an optical microscope on samples of $99.9 \% \mathrm{Sn}$, and $\mathrm{Sn}-\mathrm{Pb}$ alloys containing $0.5,10.0,30.0,38.1,50.0$, and 70.0 mass $\% \mathrm{~Pb}$ under two different temperature gradients, in order to study the influence of composition and temperature gradient on the formation of equiaxed crystals.

It was observed that the solid-liquid interface advanced from the cooling end to the hotter part in the pure $\mathrm{Sn}$, the $\mathrm{Sn}-0.5$ mass $\% \mathrm{~Pb}$ and the $\mathrm{Sn}-\mathrm{Pb}$ eutectic alloy under any temperature gradient. When the content of $\mathrm{Pb}$, in the hypo-eutectic alloy, was increased to more than 5.0 mass $\%$, the separation of equiaxed crystals from the cooling end was clearly observed under lower temperature gradient $(900$ $\mathrm{K} / \mathrm{m}$ ). Only the growth of dendritic crystals was observed, when the temperature gradient was larger $(1800 \mathrm{~K} / \mathrm{m})$. The macrostructures of these samples were fine equiaxed crystals and thick columnars. In the hypo-eutectic alloy, the floatation of primary crystals was observed during the initial stage of solidification, and the eutectic solidification finally appeared regardless the existence of primary crystals.
\end{abstract}

(Received July 4, 1984)

Keywords: tin-lead alloy, unidirectional solidification, direct observation, solidification phenomenon, cast structure, equiaxed crystals, columnar crystals, equiaxed eutectic grain

\section{Introduction}

It is well known that the macrostructure of an ingot generally consists of three different zones named the chill zone, the columnar zone and the equiaxed zone. Up to now the formation mechanism of the equiaxed central zone was considered to be the most difficult to understand, although several theories have been proposed ${ }^{(1)-(4)}$. Two of the present authors ${ }^{(5)(6)}$, on the basis of the direct observation method, proposed that the crystals nucleated on the mold wall or on the cooled-molten surface, grew in a neck-shape because of the solute segregation, then separated from the original position before the formation of a solid shell, finally, precipitated and accumulated to form the equiaxed central zone. Examining this theory, they further studied the formation of the macrosegregation of an ingot and the mechanism of grain refining ${ }^{(7)(8)}$.

In the present research the solidification phenomenon of different compositions of

* Postgraduate Student, Chiba Institute of Technology. Present address: Xi'an Jiaotong University, Xi'an, China.

** Department of Metallurgical Engineering, Chiba Institute of Technology, Narashino 275, Japan.
$\mathrm{Sn}-\mathrm{Pb}$ alloys was directly observed through a microscope under different temperature gradients, in order to know the influence of composition and temperature gradient on the formation of equiaxed crystals.

\section{Experimental Procedure}

\section{Apparatus for the direct observation}

As shown in Fig. 1, the apparatus consists of a long pyrex glass container which is about $500 \mathrm{~mm}$ long and $12 \mathrm{~mm}$ in internal diameter, and three filters. Each filter has a communicating hole (about $1 \mathrm{~mm}$ in dia.) at the bottom. About $50 \mathrm{~g}$ of specimen was put inside the uppermost filter. The container was evacuated to about $1.3 \times 10^{-3} \mathrm{~Pa}$, and then the top was sealed by melting.

The specimen was melted by a gas burner from the outside of the container to allow it to flow down to the next filter leaving oxide film behind. The same procedure was repeated in the next filter, and finally the clean metal was obtained at the bottom of the container.

Figure 2 shows the apparatus used for taking microcinematographs of the solidification phenomenon. The filtered specimen was melted in a horizontal-type electric furnace, 


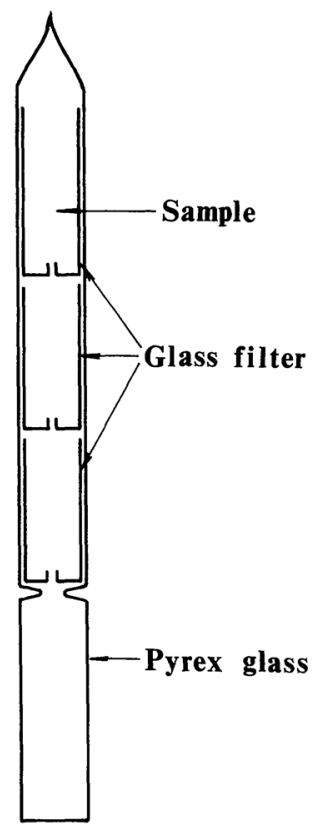

Fig. 1 Arrangement of apparatus for filtration of a metal.

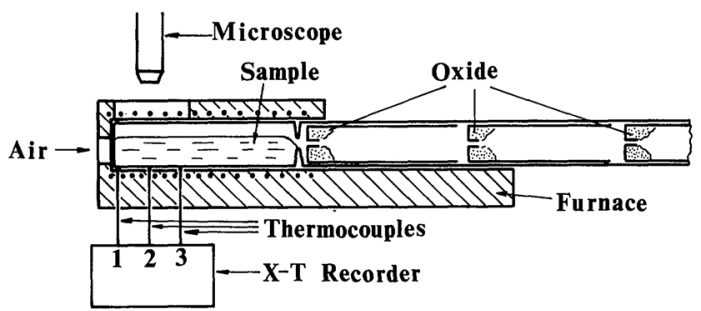

Fig. 2 Arrangement for microcinematography of solidification along a clean metal surface.

and the end of the container was cooled by compressed air. A observation hole was bored at the top of the furnace wall, and the solidification phenomenon was directly observed through the hole with an optical microscope. The composition of samples were 99.9 mass $\%$ Sn, Sn-0.5 mass $\%, 5$ mass $\%, 10$ mass $\%$, 30 mass $\%, 38.1$ mass $\%, 50$ mass $\%$, and 70 mass $\% \mathrm{~Pb}$.

The pressures of the cooling air were $1 \times 10^{5}$ $\mathrm{Pa}$ and $2 \times 10^{5} \mathrm{~Pa}$ so that the solidification speeds of the specimen were about $1.4 \times 10^{-4}$ $\mathrm{m} / \mathrm{s}$ and $1.7 \times 10^{-4} \mathrm{~m} / \mathrm{s}$, respectively, and the temperature gradients of the liquid were about $900 \mathrm{~K} / \mathrm{m}$ and $18000 \mathrm{~K} / \mathrm{m}$, respectively.

\section{The measurement of temperature}

At the cooling end, three thermocouples were set close to the glass container in the furnace, as shown in Fig. 2. There was each separation of $15 \mathrm{~mm}$ between the neighbouring thermocouples. In order to get the true temperature of the liquid specimen during the solidification, the temperature of the liquid and that outside the container were measured by the thermocouples, as shown in Fig. 3. The method of regressive analysis was used to get the relational equation between these two temperatures. So, using the equation, the nearly true temperature of the liquid specimen was able to be calculated according to the temperature measured by the thermocouples set in the furnace. The relative coefficients of all equations were all larger than 0.99 .

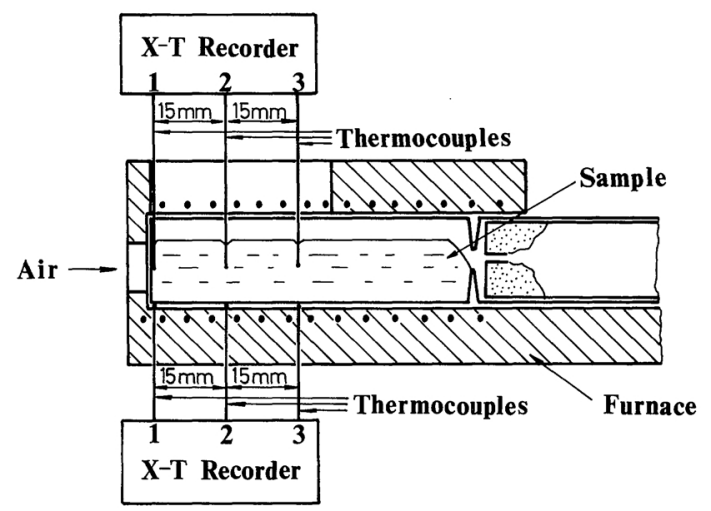

Fig. 3 Arrangement of apparatus for measure the temperatures of the liquid and the outside container.

\section{Results}

The solidification phenomenon, at first, was observed at the distance of $15 \mathrm{~mm}$ from the cooling end. Figure 4(a) shows the advancing solid-liquid interface of $99.9 \% \mathrm{Sn}$ from the left to the right. Figure 4(b) shows the solidification front of the $\mathrm{Sn}-0.5 \% \mathrm{~Pb}$ alloy. Deep ripples were observed at the solid-liquid interface.

However, in the hypo-eutectic alloy, when the $\mathrm{Pb}$ content was increased to more than $5 \%$, the advancing solid-liquid interface was not observed in the initial stage of solidification. Two different solidification phenomena were observed, as shown in Fig. 4(c) and (d). When 

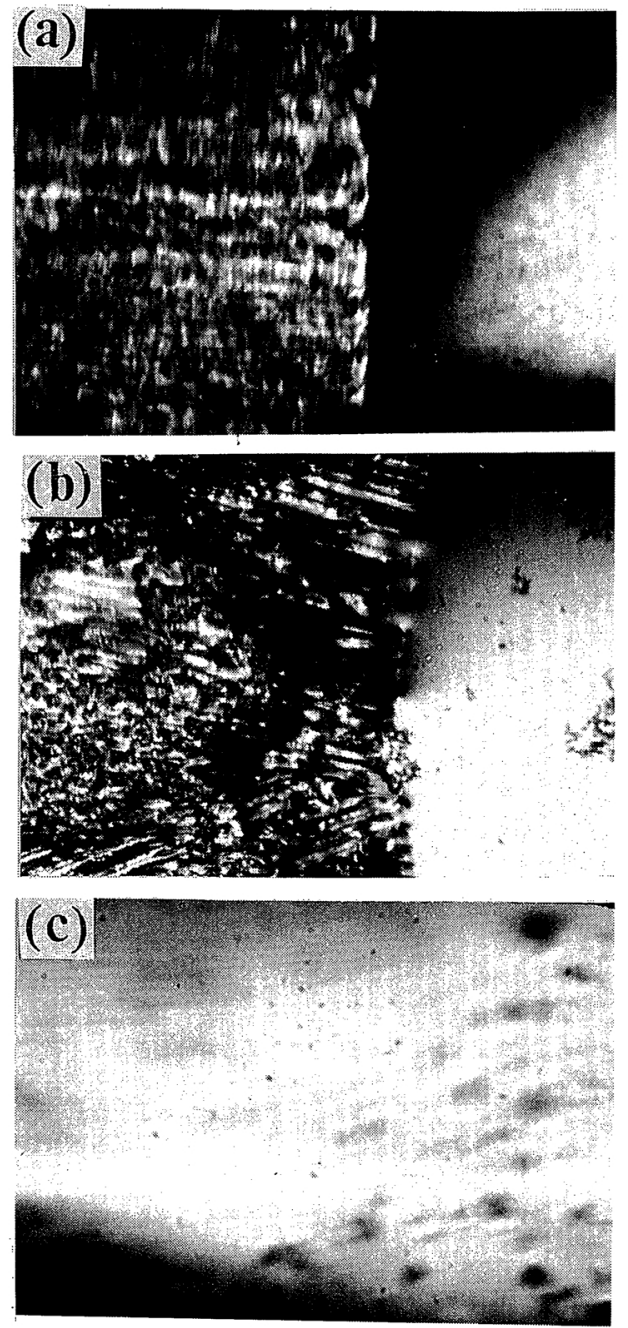
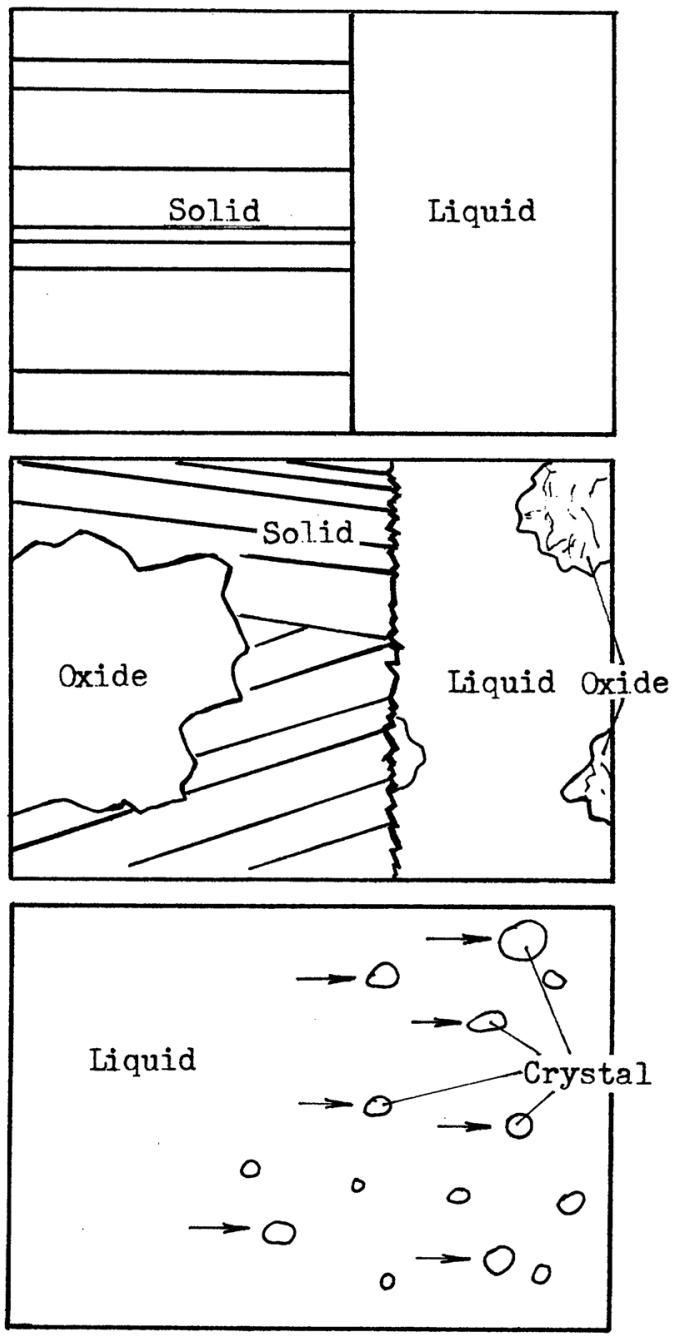

Fig. 4

the temperature gradient was small (about 900 $\mathrm{K} / \mathrm{m}$ ), free crystals which were rapidly moving toward the hotter part of the molten surface were observed, as shown in Fig. 4(c). In this case, the molten surface first moved toward the cooling end and then suddenly retreated with the free crystals moving toward the hotter part. After the movement of free crystals, dendrite tips appeared on the molten surface, and they grew until the beginning of eutectic solidification from the primary dendrite crystals. Figure 5(a) shows the appearance of the top surface of the specimen solidified in this condition. A dent on the surface on the cooling side delineates the region which was solidified at the end. Figure 5(b) shows the macrostructure of the horizontal section of the same specimen. Fine equiaxed crystals were seen in this specimen. But when the temperature gradient was large (about 18000 $\mathrm{K} / \mathrm{m}$ ), the movement of free crystals was not observed, the solidification of the liquid was only in the form of dendrite, and at last, the beginning of eutectic solidification from the dendrite tips was observed, as shown in Fig. 4(d). Figure 5(c) and (d) show the appearance of the top surface of the specimen solidified in this condition and the macrostructure of the horizontal section of the same specimen. Only thick columnar crystals were observed in Fig. 

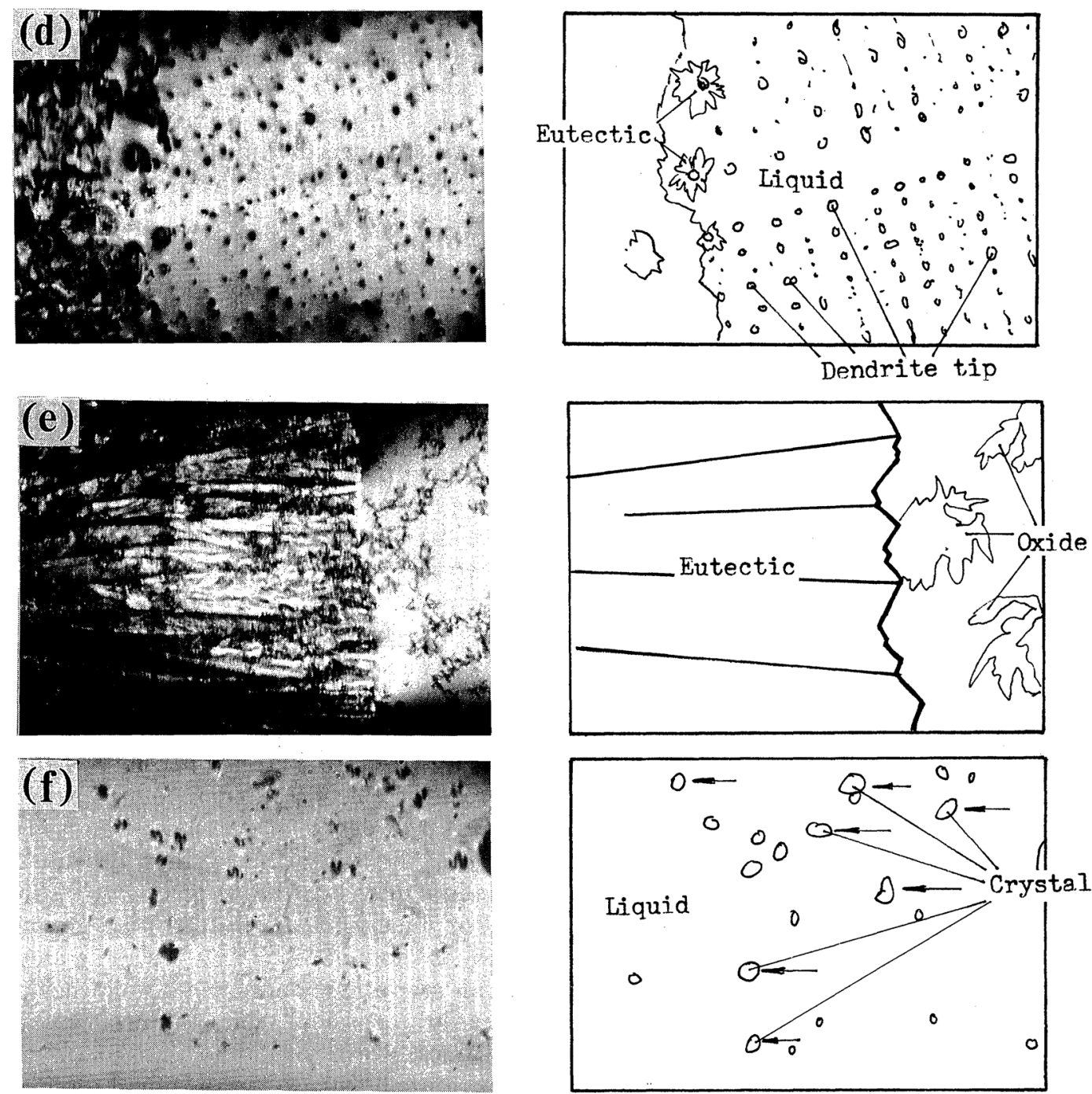

Fig. 4 Interface between solid and liquid for different tin-lead alloys observed at the distance of 15 $\mathrm{mm}$ from the cooling wall. $(\times 35 \times 0.9)$ (a) $99.9 \% \mathrm{Sn}$, (b) $\mathrm{Sn}-0.5 \% \mathrm{~Pb}$, (c) $\mathrm{Sn}-10 \% \mathrm{~Pb}$ (T. G. $=900 \mathrm{~K} / \mathrm{m}$ ), (d) Sn-10\%Pb (T. G. $=18000 \mathrm{~K} / \mathrm{m}$ ), (e) Sn-38.1\%Pb, (f) Sn-70\%Pb.

5(d). Figure 6(a) and (b) are cooling curves of these two solidification conditions calculated by relational equations according to the cooling curves measured by the thermocouples set in the furnace. These show the true temperature of the liquid during the solidification.

In order to observe the formation and separation of the free crystals, the solidification phenomenon at the cooling wall was observed. Figure 7 shows the solidification phenomenon in the $\mathrm{Sn}-10 \% \mathrm{~Pb}$ alloy in the initial stage of solidification. The nucleation oc- curred on the mold wall, and the crystals grew in a granular shape and then separated away from the mold wall. The same solidification phenomenon was also observed in the case of the $\mathrm{Sn}-30 \% \mathrm{~Pb}$ alloy.

Figure 4(e) shows the solid-liquid interface of the $\mathrm{Sn}-38.1 \% \mathrm{~Pb}$ alloy (eutectic composition). The advancing columnar eutectic grains were observed. In this case, the molten surface current always moved toward the cooling end.

When the $\mathrm{Pb}$ content was increased over the $38.1 \%$, the advancing solid-liquid interface, 
(a)
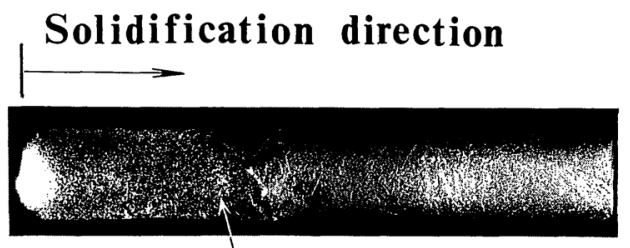

Depression

(b)

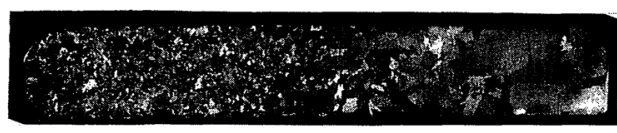

(c)

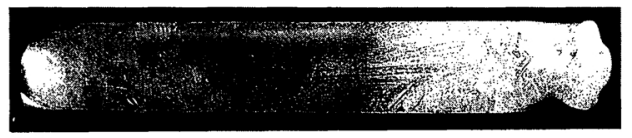

(d)

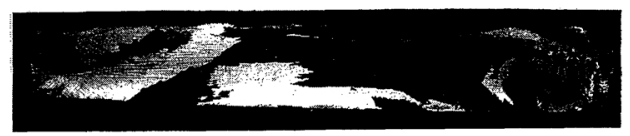

Fig. 5 Appearances and macrostructures of $\mathrm{Sn}-10 \% \mathrm{~Pb}$ alloy solidified at two different temperature gradients $(\times 1.1 \times 0.6)$.

(a) Appearance (T. G. $=900 \mathrm{~K} / \mathrm{m}$, (b) Macrostructure (T. G. $=900 \mathrm{~K} / \mathrm{m}$ ), (c) Appearance (T. G. $=18000$ $\mathrm{K} / \mathrm{m}$ ), (d) Macrostructure (T. G. $=1800 \mathrm{~K} / \mathrm{m}$ ).
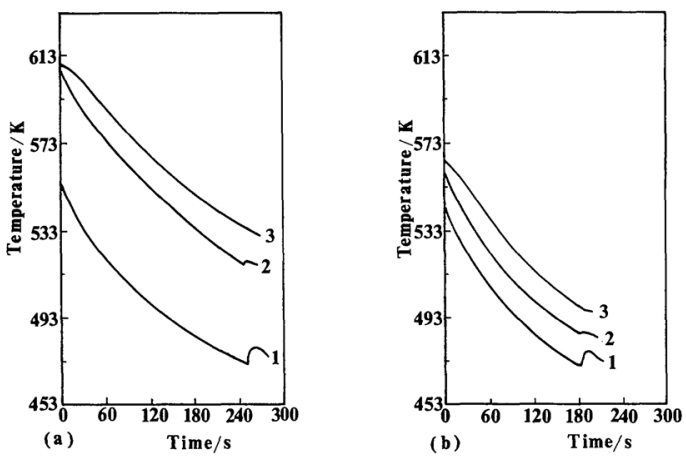

Fig. 6 Cooling curves of $\mathrm{Sn}-10 \% \mathrm{~Pb}$ alloy at different positions in liquid.

(a) The pressure of cooling air is $2 \times 10^{5} \mathrm{~Pa}$,

(b) The pressure of cooling air is $1 \times 10^{5} \mathrm{~Pa}$.

the movement of the free crystals from the cooling end and the retreat of the molten surface were not observed. Rather, only the floata- tion of fine crystals was observed on the molten surface, which moved toward the cooling end in the initial stage of solidification as shown in Fig. 4(f). The primary crystals grew until the commencement of eutectic solidification from the cooling end, regardless of primary crystals.

\section{Discussion}

\section{The formation of equiaxed crystals}

When molten pure $\mathrm{Sn}$ is cooled on a mold wall, the crystals nucleated on the mold wall grow along the mold wall, until it touches the neighbouring crystals to form stable solid shell on the mold wall as shown in Fig. 8, since the temperature of the liquid is the lowest at this position.

However, with the increase of the $\mathrm{Pb}$ content, the nucleated crystals will grow along the mold wall at first, but the enrichment of $\mathrm{Pb}$ will occur at the advancing solid-liquid interface. So the freezing temperature will be decreased, and the undercooling will be lowered. The degree of $\mathrm{Pb}$ segregation is more serious at the root of the crystals, because the $\mathrm{Pb}$ cannot diffuse toward the mold wall, so the head of the crystals begin to form a granular shape, as shown in Fig. 9. When the granular crystals are formed on the mold wall, they can be easily separated from the wall by the mechanical force of liquid convection and temperature fluctuation in the liquid produced by the convection. In the hypo-eutectic alloy, the separated crystals will float along the mold wall, because the specific gravity of Sn-rich primary crystals is less than that of the liquid. The floating crystals will further promote the separation of the crystals on the upper wall of the mold, and finally, the current of floating crystals will force the convection to retreat from their usual direction and to move toward the hotter part, as shown in Fig. 10(a).

On the other hand, for the alloy of hypereutectic, the specific gravity of $\mathrm{Pb}$-rich primary crystals is larger than that of the liquid, therefore, the primary crystals will precipitate along the mold wall and be carried toward the hotter part of the molten metal by the convec- 

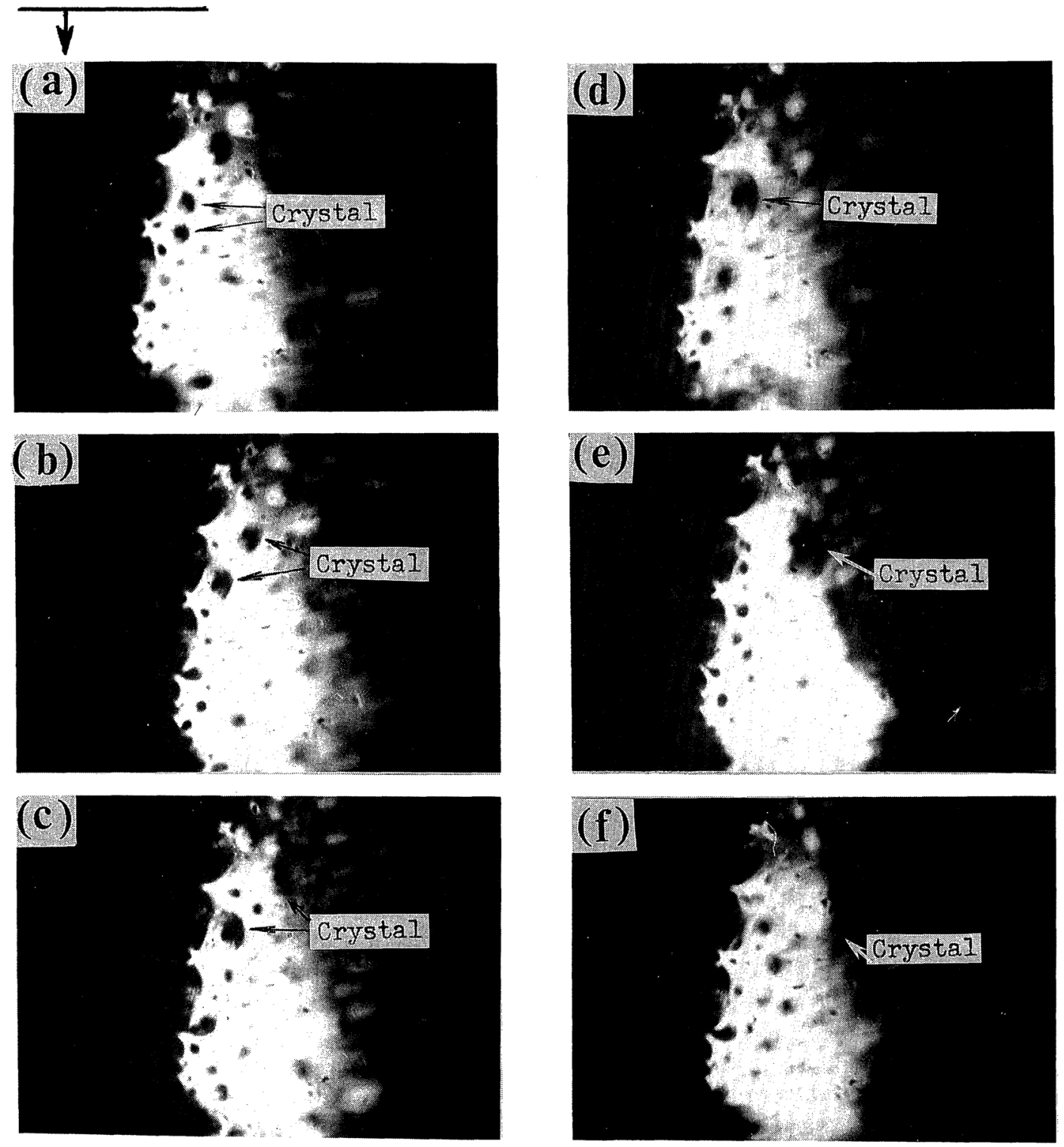

Fig. 7 Separation of equiaxed crystals of $\mathrm{Sn}-10 \% \mathrm{~Pb}$ alloy from the mold wall. (Enlargements from the motion picture filmed at 24 frames $/ \mathrm{s})(\times 35 \times 0.95)$

tion of the liquid. Finally, a part of the crystals will be carried to the molten surface, as shown in Fig. 10(b).

\section{The influence of temperature gradient on the formation of equiaxed crystals}

From the cooling curves of Fig. 6, the equations of temperature distribution at the time of nucleation are expressed as follows;

$$
\text { for Fig. } 6(\mathrm{a}) ; \quad T_{\mathrm{a}}=197+18 \ln (X+1)
$$

and

$$
\text { for Fig. 6(b); } \quad T_{\mathrm{b}}=195+X,
$$

where $T$ is the liquid temperature $(\mathrm{K})$ and $X$ is the distance $(\mathrm{mm})$ from cooling end. The 


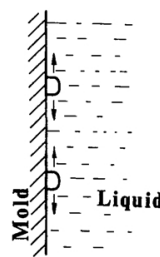

(a)

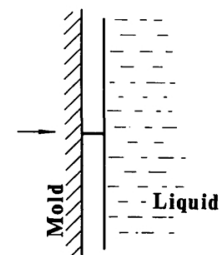

(b)

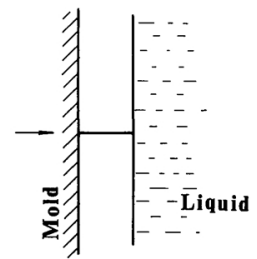

(c)
Fig. 8 Schematic illustration of the solidification phenomenon of pure Sn at the mold wall.

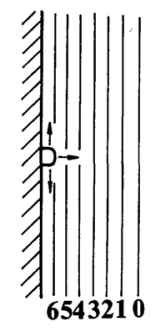

(a)

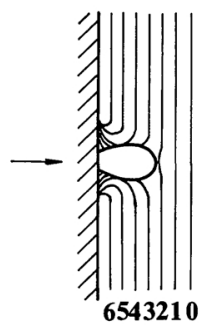

(b)

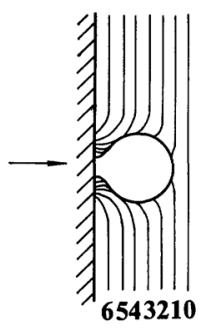

(c)
Fig. 9 Schematic illustration of the undercooling at the solid-liquid interface of a crystal which is growing on the mold wall.

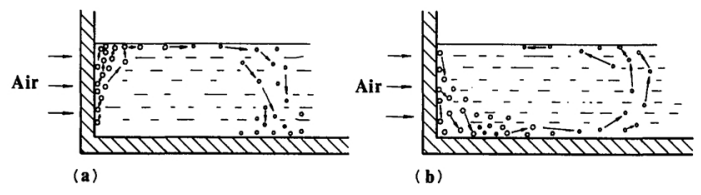

Fig. 10 Schematic illustration of the crystals movement in the initial stage of solidification.

relative coefficients of the equations are all larger than 0.99 .

The temperature gradient of the liquid at the mold wall $\left(G_{0}\right)$ is obtained by differentiating $T$ with the distance $X$ and setting the $X$ to approach the limit zero. That is;

$$
G_{\mathrm{ao}}=\mathrm{d} T_{\mathrm{a}} /\left.\mathrm{d} X\right|_{x \rightarrow 0}=18
$$

and

$$
G_{\mathrm{bo}}=\mathrm{d} T_{\mathrm{b}} /\left.\mathrm{d} X\right|_{x \rightarrow 0}=1,
$$

and they are expressed as in Fig. 11(a) and (b). Therefore, when a crystal nucleated on the mold wall (as shown in (c) and (d) of Fig. 11) the temperatures of local interface, because of the difference in temperature gradient, are different from each other (as shown by (a') and (b') of the same figure.). In other words, the
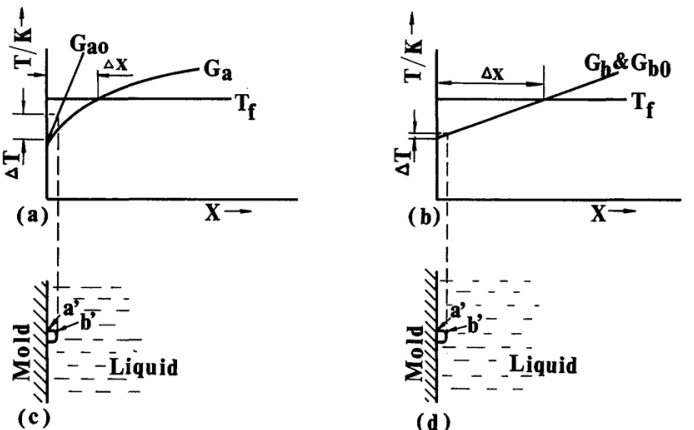

Fig. 11 Schematic illustration of the influence of temperature gradient on the formation of neck-shape crystals.

undercoolings at the place (a') and (b') are different from each other. Clearly, the greater the temperature gradient, the larger the difference in temperature $(\Delta T)$ between ( $\left.\mathrm{a}^{\prime}\right)$ and (b'), as shown in Fig. 11, as well as, the smaller the undercooling at the place (b'). So, in the same condition of composition segregation the growth at (b') is much slower in the larger temperature graident than that in the smaller temperature gradient. Moreover, with the increase of temperature graident, the undercooling region of the liquid $(\Delta X)$, near the cooling wall, narrows as shown in Fig. 11(a) and (b). So, the growth of the crystals will be restrained, and it also makes separation difficult. Furthermore, when the pressure of the cooling air is increased, the speed of cooling will become more rapid on the mold wall, and therefore, many crystals will nucleate close to each other on the mold wall, and the stable solid shell will be rapidly formed.

For the reasons mentioned above, the crystals formed on the mold wall separate difficultly and a stable solid shell forms easily. Finally, the columnar structure is formed in the sample, as shown in Fig. 5(d).

\section{Conclusion}

The solidification phenomenon was directly observed through an optical microscope on samples of different compositions of $\mathrm{Sn}-\mathrm{Pb}$ alloys.

(1) For pure Sn the planer advancing solidliquid interface was clearly observed. Deep ripples were formed in the solid-liquid interface, 
with the increase of $\mathrm{Pb}$ content, and finally, the advancing solid-liquid interface was unable to be observed, when the $\mathrm{Pb}$ content was increased over $5 \%$.

(2) In the inital stage of solidification, for $\mathrm{Sn}-10 \% \mathrm{~Pb}$ and $\mathrm{Sn}-30 \% \mathrm{~Pb}$ alloys, the formation of equiaxed crystals on the mold wall and the separation of crystals were clearly observed, when temperature graident was small. The macrostructure of the sample solidified in this condition consisted of fine equiaxed crystals. On the other hand, only the growth of dendrite crystals was observed and the macrostructure of the sample was thick columnars, when the temperature gradient was large. So, the separation of equiaxed crystals from the mold wall during the inital stage of solidification is considered to be the most responsible cause for the fomation of fine equiaxed structure, and the temperature gradient had the great influence on the formation of equiaxed crystals.

(3) For the hyper-eutectic alloy, the floatation of primary crystals and the movement of them with the current of convection of the liquid were observed.

\section{REFERENCES}

(1) W. C. Winegard and B. Chalmers: Trans. ASM, 46 (1954), 1214.

(2) H. Bilony and Chalmers: J. Aust. Inst. Met. 8 (1963), 255.

(3) K. A. Jackson, J. D. Hunt, D. R. Uhlmann and T. P. Seward III: Trans. Met. Soc. AIME, 236 (1966), 149.

(4) R. T. Southin: Trans. Met. Soc. AIME, 239 (1967), 220.

(5) A. Ohno, T, Motegi and H. Soda: Trans. ISIJ, 11 (1971), 18.

(6) A. Ohno: The solidification of metals, Chijin Shokan, Tokyo, (1976), p. 54.

(7) T. Motegi and A. Ohno: J. Japan Inst. Metals, 45, (1981), 1215 (in Japanese).

(8) T. Motegi and A. Ohno: Keikinzoku (J. Japan Inst. Light Met.), 31 (1981), 415 (in Japanese). 